\title{
Knockdown of IncRNA TUG1 protects lens epithelial cells from oxidative stress-induced injury by regulating miR-196a-5p expression in age-related cataracts
}

\author{
QIMIN SHEN and TIAN ZHOU \\ Department of Ophthalmology, People's Hospital of Yuyao, Ningbo, Zhejiang 315400, P.R. China
}

Received February 23, 2021; Accepted June 18, 2021

DOI: $10.3892 /$ etm.2021.10721

\begin{abstract}
Oxidative stress plays an important role in the pathogenesis of cataracts. Under oxidative stress, apoptosis of lens epithelial cells (LECs) is activated, which may cause lens opacity and accelerate the development of cataracts. Long non-coding RNA (IncRNA) and microRNA (miRNA/miR) are involved in cataracts. Previous studies have demonstrated that lncRNA taurine upregulated 1 (TUG1) promotes cell apoptosis induced by ultraviolet radiation by downregulating the expression of miR-421. However, the mechanism underlying TUG1 in age-related cataract remains to be elucidated. The present study aimed to investigate the effect of TUG1 in age-related cataracts and to determine the related underlying molecular mechanism. In the present study, the association between TUG1 and microRNA (miR)-196a-5p was predicted using StarBase and verified using a dual luciferase reporter assay in 293 cells. The LEC line SRA01/04 was exposed to $200 \mu \mathrm{M}$ hydrogen peroxide $\left(\mathrm{H}_{2} \mathrm{O}_{2}\right)$ for $24 \mathrm{~h}$ to establish an in vitro oxidative stress model. The mRNA expression levels of TUG1 and miR-196a-5p were analyzed using reverse transcription-quantitative PCR, whilst cell viability and apoptosis were determined using MTT and flow cytometry assays, respectively. The protein expression levels of cleaved caspase-3 and caspase-3 in SRA01/04 cells were determined using western blotting. The results of the present study revealed that TUG1 directly targeted miR-196a-5p expression. In addition, the expression levels of miR-196a-5p were downregulated in SRA01/04 cells following oxidative stress, whilst TUG1 expression was upregulated. Cell transfection with TUG1-small interfering RNA (siRNA) upregulated miR-196a-5p expression levels in SRA01/04 cells, which was reversed following co-transfection with the miR-196a-5p inhibitor. Transfection with TUG1-siRNA also reduced the
\end{abstract}

Correspondence to: Dr Tian Zhou, Department of Ophthalmology, People's Hospital of Yuyao, 800 Chengdong Road, Ningbo, Zhejiang 315400, P.R. China

E-mail: zhoutian142223@163.com

Key words: age-related cataracts, lens epithelial cells, taurine upregulated 1, microRNA-196a-5p levels of $\mathrm{H}_{2} \mathrm{O}_{2}$-induced oxidative damage in SRA01/04 cells, which was demonstrated by increased cell viability, reduced levels of apoptosis and downregulated cleaved caspase-3 levels. Conversely, transfection with the miR-196a-5p inhibitor reversed these effects aforementioned. Overexpression of miR-196a-5p reduced $\mathrm{H}_{2} \mathrm{O}_{2}$-induced oxidative damage in SRA01/04 cells. In conclusion, findings from the present study suggested that knocking down TUG1 expression may protect LECs from oxidative stress-induced apoptosis by upregulating the expression of miR-196a-5p.

\section{Introduction}

Cataracts can occur due to various factors, including aging, a familial history, immune and metabolic abnormalities, trauma to the eye and exposure of the eye to poison or radiation $(1,2)$. Cataracts can lead to lens protein degeneration and opacity (3). At present, age-related cataracts is the most common type of cataracts (4-6). Cataracts commonly develop in middle-aged and elderly individuals aged $>50$, where the incidence increases with age (7). Age-related cataracts are associated with the natural degeneration of the lens, which occurs over time during old age (8). Clinically, age-related cataracts can be divided into three subtypes, namely cortical, nuclear and posterior subcapsular cataracts $(9,10)$. There is currently no strict distinction between these various subtypes of age-related cataracts, but all can progress into the total calcification of the lens (11). Cortical cataracts are the most common type of age-related cataracts, accounting for 65-70\% of all age-related cataract cases, followed by nuclear cataracts, accounting for $25-35 \%$ of cases and finally subcapsular opacity cataracts, which are relatively rare and only account for $5 \%$ of all age-related cataracts $(12,13)$. Age-related cataracts is one of the main causes of blindness, and the incidence rate increases with age. Worldwide, patients aged 43-54 years have an incidence rate of $8.3 \%$, compared with an incidence as high as $70.5 \%$ in patients $>75$ years-old $(14,15)$. It was previously discovered that oxidative stress serves an important role in the pathogenesis of cataracts. Under oxidative stress, apoptosis is induced in lens epithelial cells (LECs), which was found to promote the opacification of the lens and accelerate the development of cataracts $(16,17)$. Therefore, the present study used human LECs to study the pathogenesis of age-related cataracts. 
Long non-coding RNAs (lncRNAs) are a type of non-coding RNA that are $>200$ nucleotides in length but lack protein coding ability $(18,19)$. Although lncRNAs do not generally encode protein, they participate in the regulation of protein-coding gene expression at multiple levels, including epigenetic, transcriptional and post-transcriptional regulation $(20,21)$. MicroRNAs (miRNAs/miRs) are a type of endogenous non-coding small RNA that are 21-25 nucleotides in length and exist in both animals and plants $(22,23)$. The tissue specificity of miRNA and the time at which they are expressed determines their functional specificity in tissues and cells (24). This suggests that miRNAs can serve important roles in the regulation of cell proliferation, in addition to having a key role in the regulation of post-transcriptional gene expression. It was previously reported that the dysregulated expression levels of IncRNAs and miRNAs were associated with the occurrence of cataracts (25-27). For example, Chen et al (25) demonstrated that increased expression of miR-26a and miR-26b inhibited lens fibrosis and cataract formation by regulating the Jagged-1/Notch signaling pathway. Zhang et al (26) previously found that downregulation of miRNA-133b suppressed apoptosis of LECs by upregulating BCL2L2 in age-related cataracts. In addition, the expression of TUG1 in the anterior lens capsules of age-related cataract were revealed to be significantly higher compared with normal anterior lens capsules, where TUG1 promoted ultraviolet radiation-induced apoptosis by downregulating the expression of miR-421 (27).

miR-196a-5p has been studied in various diseases, including cancer, pre-eclampsia and postmenopausal osteoporosis (28-30). miR-196a-5p serves a key role in the regulation of tumor cell apoptosis and proliferation $(31,32)$. However, the effects of miR-196a-5p on age-related cataracts and in lens epithelial cells remain unclear.

The present study aimed to investigate the effects of TUG1 in oxidative stress-induced apoptosis in age-related cataracts and to determine its underlying mechanism of action, with a focus on providing novel insights into potential therapeutic targets for cataracts.

\section{Materials and methods}

Cell culture and establishment of oxidative stress model. SRA01/04 cells, a human LEC line, were obtained from the American Type Culture Collection (ATCC). SRA01/04 cells were cultured in RPMI-1640 medium (Gibco; Thermo Fisher Scientific, Inc.) supplemented with $10 \%$ FBS (Gibco; Thermo Fisher Scientific, Inc.) and $1 \%$ penicillin/streptomycin, which were maintained at $37^{\circ} \mathrm{C}$ with $5 \% \mathrm{CO}_{2}$.

To establish an in vitro oxidative stress model, SRA01/04 cells were exposed to $200 \mu \mathrm{M}$ hydrogen peroxide $\left(\mathrm{H}_{2} \mathrm{O}_{2}\right)$ at $37^{\circ} \mathrm{C}$ for $24 \mathrm{~h} \mathrm{(33).}$

Cell transfection. SRA01/04 cells were cultured in six-well plates at $37^{\circ} \mathrm{C}$ for $24 \mathrm{~h}$ and then transfected with $200 \mathrm{pmol} / 1$ control small interfering RNA (siRNA; sense, 5'-UUCUCC GAACGUGUCACGUTT-3'; antisense, 3'-ACGUGACAC GUUCGGAGAATT-5'; Shanghai GenePharma Co., Ltd.), 200 pmol/1 TUG1-siRNA (sense, 5'-CCAUCUCACAAGGCU UCA ATT-3'; antisense, 3'-TTGGUAGAGUGUUCCGAA GUU-5'; Shanghai GenePharma Co., Ltd.), 50 nM inhibitor control (5'-CAGUACUUUUGUGUAGUACAA-3'; Shanghai GenePharma Co., Ltd.), 50 nM miR-196a-5p inhibitor (5'-CCC AACAACAUGAAACUACCUA-3'; Shanghai GenePharma Co., Ltd.), 100 nM mimic control (sense, 5'-UUCUCCGAA CGUGUCACGUTT-3'; antisense, 5'-ACGUGACACGUU CGGAGAATT-3'; Shanghai GenePharma Co., Ltd.) or 100 nM miR-196a-5p mimic (sense, 5'-UAGGUAGUUUCA UGUUGUUGGG-3'; antisense, 5'-CAACAACAUGAAACU ACCUAUU-3'; Shanghai GenePharma Co., Ltd.) for $24 \mathrm{~h}$ using Lipofectamine ${ }^{\circledR} 2000$ reagent (Invitrogen; Thermo Fisher Scientific, Inc.). Following transfection, the cells were collected to determine the transfection efficiencies by reverse transcription-quantitative PCR (RT-qPCR).

To determine the effect of TUG1-siRNA in SRA01/04 cells exposed to $200 \mu \mathrm{M} \mathrm{H}_{2} \mathrm{O}_{2}$, cells were divided into the following groups: i) Control group, with cells without any treatment; ii) $\mathrm{H}_{2} \mathrm{O}_{2}$ group, where the SRA01/04 cells were exposed to $200 \mu \mathrm{M} \mathrm{H}_{2} \mathrm{O}_{2}$ at $37^{\circ} \mathrm{C}$ for $24 \mathrm{~h}$; iii) $\mathrm{H}_{2} \mathrm{O}_{2}+$ control-siRNA group, where SRA01/04 cells were transfected with control-siRNA for $24 \mathrm{~h}$ and then exposed to $200 \mu \mathrm{M}$ $\mathrm{H}_{2} \mathrm{O}_{2}$ at $37^{\circ} \mathrm{C}$ for $24 \mathrm{~h}$; iv) $\mathrm{H}_{2} \mathrm{O}_{2}+$ TUG1-siRNA group, where SRA01/04 cells were transfected with TUG1-siRNA for $24 \mathrm{~h}$ and then exposed to $200 \mu \mathrm{M} \mathrm{H}_{2} \mathrm{O}_{2}$ at $37^{\circ} \mathrm{C}$ for $24 \mathrm{~h}$; v) $\mathrm{H}_{2} \mathrm{O}_{2}$ + TUG1-siRNA + inhibitor control group, where SRA01/04 cells were co-transfected with the TUG1-siRNA + inhibitor control for $24 \mathrm{~h}$ and then exposed to $200 \mu \mathrm{M} \mathrm{H}_{2} \mathrm{O}_{2}$ at $37^{\circ} \mathrm{C}$ for $24 \mathrm{~h}$; and vi) $\mathrm{H}_{2} \mathrm{O}_{2}+$ TUG1-siRNA + miR-196a-5p inhibitor group, where SRA01/04 cells were co-transfected with TUG1-siRNA + miR-196a-5p inhibitor for $24 \mathrm{~h}$ and then exposed to $200 \mu \mathrm{M} \mathrm{H}_{2} \mathrm{O}_{2}$ at $37^{\circ} \mathrm{C}$ for $24 \mathrm{~h}$.

To determine the effect of the miR-196a-5p mimic on SRA01/04 cells following exposure to $200 \mu \mathrm{M} \mathrm{H}_{2} \mathrm{O}_{2}$, cells were divided into the following groups: i) Control group, which consists of cells without any treatment; ii) $\mathrm{H}_{2} \mathrm{O}_{2}$ group, where SRA01/04 cells were exposed to $200 \mu \mathrm{M} \mathrm{H}_{2} \mathrm{O}_{2}$ at $37^{\circ} \mathrm{C}$ for $24 \mathrm{~h}$; iii) $\mathrm{H}_{2} \mathrm{O}_{2}+$ mimic group, where SRA01/04 cells were transfected with the mimic control for $24 \mathrm{~h}$ and then exposed to $200 \mu \mathrm{M} \mathrm{H}_{2} \mathrm{O}_{2}$ at $37^{\circ} \mathrm{C}$ for $24 \mathrm{~h}$; and iv) $\mathrm{H}_{2} \mathrm{O}_{2}+$ miR-196a-5p mimic group, where SRA01/04 cells were transfected with miR-196a-5p mimic for $24 \mathrm{~h}$ and then exposed to $200 \mu \mathrm{M}$ $\mathrm{H}_{2} \mathrm{O}_{2}$ at $37^{\circ} \mathrm{C}$ for $24 \mathrm{~h}$.

miRNA target analysis and dual-luciferase reporter assay. The direct binding site between TUG1 and miR-196a-5p was identified using StarBase version 2.0 (http://starbase. sysu.edu.cn/). The 3'-untranslated region (UTR) sequences of TUG1 [TUG1-wild-type (WT), 5'-AUCGUCAAUUUU CUACUACCUU-3'], which included the target sequence for miR-196a-5p, or the mutated (MUT) target site (TUG1-MUT, 5'-AUGGUGUUUUAUCUUGAUGGAU-3') were obtained by PCR using a Transcriptor First Strand cDNA Synthesis kit (cat. no. 04896866001; Roche Diagnostics GmbH). The thermocycling conditions were as follows: Incubation for $5 \mathrm{~min}$ at $25^{\circ} \mathrm{C}$, followed by $60 \mathrm{~min}$ at $42^{\circ} \mathrm{C}$. The $3^{\prime}$-UTR products were cloned into the pmirGLO vector (Promega Corporation) to construct the TUG1-WT reporter vector. In addition, a TUG1-MUT reporter vector was also generated. 293 cells were obtained from the ATCC and cultured in Eagle's Minimum Essential Medium (ATCC) supplemented with 10\% FBS (Gibco; Thermo Fisher Scientific, 
Inc.) at $37^{\circ} \mathrm{C}$ with $5 \% \mathrm{CO}_{2}$. Briefly, 293 cells were cultured for $24 \mathrm{~h}$ before being co-transfected with $1 \mathrm{ng}$ TUG1-WT or $1 \mathrm{ng}$ TUG1-MUT luciferase reporter gene plasmid and $100 \mathrm{nM}$ miR-196a-5p mimic or $100 \mathrm{nM}$ mimic control using Lipofectamine ${ }^{\circledR} 2000$ reagent for $48 \mathrm{~h}$. The relative luciferase activity was measured using a Dual Luciferase Reporter assay system (Promega Corporation), according to the manufacturer's protocol. The results were normalized to Renilla luciferase activity.

$R T-q P C R$. Total RNA was extracted from cells using the TRIzol ${ }^{\circledR}$ reagent (Invitrogen; Thermo Fisher Scientific Inc.). Total RNA was reverse transcribed into cDNA using a Maxima First Strand cDNA synthesis kit (Invitrogen; Thermo Fisher Scientific, Inc.). The reaction conditions for RT-PCR were as follows: $70^{\circ} \mathrm{C}$ for $5 \mathrm{~min}, 37^{\circ} \mathrm{C}$ for $5 \mathrm{~min}$ and $42^{\circ} \mathrm{C}$ for 60 min. $\mathrm{qPCR}$ was performed in an ABI Prism 7000 Real-Time PCR Detection system (Applied Biosciences; Thermo Fisher Scientific, Inc.) using a SYBR ${ }^{\mathrm{TM}}$-Green qPCR Master mix (Thermo Fisher Scientific, Inc.), according to the manufacturer's protocol. The primers used for the qPCR were synthesized by Genscript and primer sequences were listed as the following: GAPDH forward, 5'-CTTTGGTAT CGTGGAAGGACTC-3' and reverse, 5'-GTAGAGGCAGGG ATGATGTTCT-3'; U6 forward, 5'-GCTTCGGCAGCACAT ATACTAAAAT-3' and reverse, 5'-CGCTTCACGAATTTG CGTGTCAT-3'; TUG1 forward: 5'-GACCGTCCAATGACC TTCCT-3' and reverse, 5'-TGGCTGAATGCTTCTTGG GT-3' and miR-196a-5p forward, 5'-CCGACGTAGGTAGTT TCATGTT-3' and reverse, 5'-GTGCAGGGTCCGAGGTAT TC-3'. The following thermocycling conditions were used for the qPCR: Initial denaturation for $5 \mathrm{~min}$ at $95^{\circ} \mathrm{C}$; followed by 40 cycles for $10 \mathrm{sec}$ at $95^{\circ} \mathrm{C}$ and $30 \mathrm{sec}$ at $60^{\circ} \mathrm{C}$. GAPDH or U6 were used as the internal controls for TUG1 and miR-196a-5p, respectively. The relative mRNA expression levels of TUG1 and miR-196a-5p were calculated using the $2^{-\triangle \Delta C q}$ method (34).

MTT assay. MTT assay was performed to evaluate cell viability. Briefly, $24 \mathrm{~h}$ after cell transfection, SR A01/04 cells were exposed to $200 \mu \mathrm{M} \mathrm{H}_{2} \mathrm{O}_{2}$ at $37^{\circ} \mathrm{C}$ for another $24 \mathrm{~h}$, before the cells were seeded into a 96 -well plate $\left(1 \times 10^{4}\right.$ cells per well). They were then treated with $10 \mu 15 \mathrm{mg} / \mathrm{ml}$ MTT solution (Beyotime Institute of Technology) per well and incubated at $37^{\circ} \mathrm{C}$ for an additional $4 \mathrm{~h}$. Following incubation, the medium was removed and $100 \mu 1$ DMSO was added to each well to dissolve the formazan product. The absorbance was measured at a wavelength of $570 \mathrm{~nm}$ using a microplate reader (Bio-Rad Laboratories, Inc.).

Flow cytometry analysis of apoptosis. Flow cytometry analysis was used to detect cell apoptosis. Briefly, following transfection, the cells were harvested by trypsinization and resuspended in 1X buffer (Annexin V-FITC/PI apoptosis detection kit; Beyotime Biotechnology). In total, $100 \mu 1$ of this cell suspension $\left(1 \times 10^{6}\right.$ cells $)$ was incubated with $5 \mu \mathrm{l}$ Annexin V-FITC and propidium iodide at $4^{\circ} \mathrm{C}$ in the dark for $15 \mathrm{~min}$. The stained cells were analyzed using a BD FACSCalibur ${ }^{\mathrm{TM}}$ flow cytometer (BD Biosciences) and FlowJo software (version 7.2.4; FlowJo LLC).
A
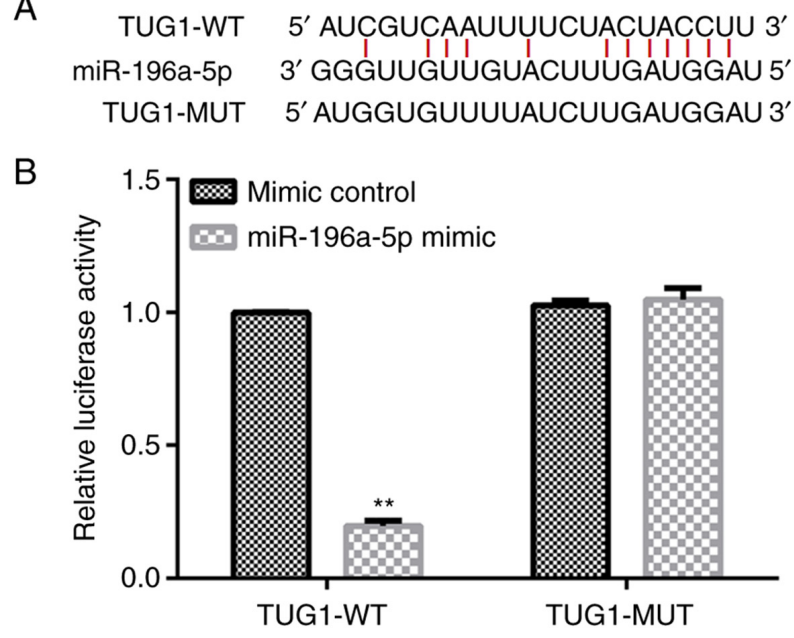

Figure 1. Identification of a direct binding site between TUG1 and miR-196a-5p. (A) Starbase was used to predict the existence of a binding site between TUG1 and miR-196a-5p. (B) 293 cells were co-transfected with a TUG1-WT or TUG1-MUT 3'-untranslated region reporter vector and miR-196a-5p mimic or mimic control. Following $48 \mathrm{~h}$ of transfection, the relative luciferase activity was measured using a dual luciferase reporter assay. ${ }^{* *} \mathrm{P}<0.01$ vs. mimic control. TUG1, taurine upregulated 1 ; miR or miRNA, microRNA; WT, wild-type; MUT, mutant.

Western blotting. Total protein was extracted from SRA01/04 cells using RIPA lysis buffer (Beyotime Institute of Biotechnology) and the lysate was centrifuged at $4^{\circ} \mathrm{C}$ at $10,000 \times \mathrm{g}$ for $15 \mathrm{~min}$ to obtain the total protein. Total protein (40 $\mu \mathrm{g}$ per lane) was quantified using a BCA protein assay kit (Bio-Rad Laboratories, Inc.) and separated by $10 \%$ SDS-PAGE. The separated proteins were subsequently transferred onto PVDF membranes and blocked with 5\% non-fat milk diluted in PBS-0.1\% Tween-20 (PBST) solution at room temperature for $1 \mathrm{~h}$. The membranes were then incubated with the following primary antibodies overnight at $4^{\circ} \mathrm{C}$ : Anti-cleaved caspase-3 (cat. no. ab32042; 1:1,000; Abcam), anti-caspase-3 (cat. no. ab32351; 1:1,000; Abcam) and anti-GAPDH (cat. no. ab9485; 1:1,000; Abcam). Following primary antibody incubation, the membranes were washed three times with PBST and incubated with a goat anti-rabbit IgG H\&L (HRP) pre-adsorbed (cat. no. ab97080; 1:2,000; Abcam) for $1 \mathrm{~h}$ at room temperature. Protein bands were visualized using an ECL substrate (Cytiva), according to the manufacturer's protocol on an ImageQuant800 western blotting imaging system (Amersham; Cytiva).

Statistical analysis. Data are presented as the mean \pm SD from three independent experiments. Statistical differences among groups were determined using an unpaired Student's t-test or one-way ANOVA followed by Tukey's post-hoc test. $\mathrm{P}<0.05$ was considered to indicate a statistically significant difference.

\section{Results}

TUG1 is a direct target gene of miR-196a-5p. Analysis using the StarBase database identified a binding site between TUG1 and miR-196a-5p (Fig. 1A), where this binding between TUG1 and miR-196a-5p was validated using a dual luciferase reporter assay (Fig. 1B). Compared with that in cells co-transfected with 

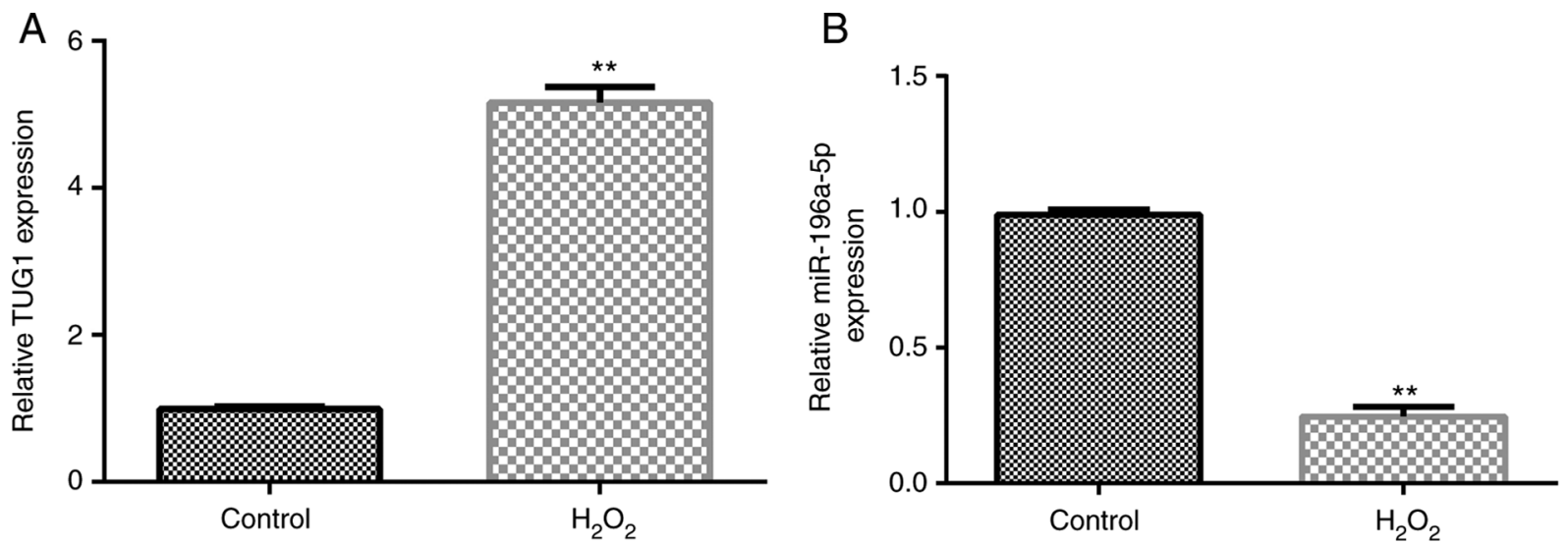

Figure 2. Expression levels of TUG1 and miR-196a-5p in SRA01/04 cells after treatment with hydrogen peroxide. Reverse transcription-quantitative PCR was used to analyze the mRNA expression levels of (A) TUG1 and (B) miR-196a-5p in SRA01/04 cells. ${ }^{* *} \mathrm{P}<0.01$ vs. control. TUG1, taurine upregulated 1; miR, microRNA.
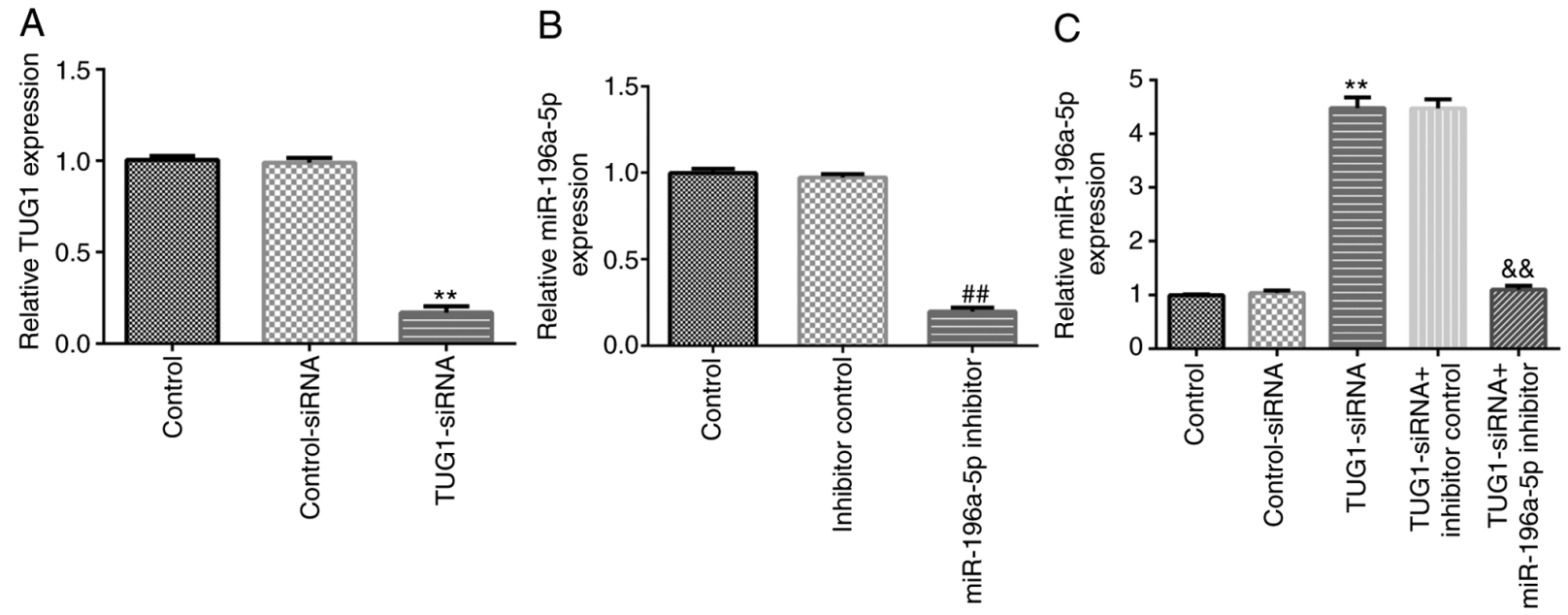

Figure 3. Transfection efficiency of TUG1-siRNA and miR-196a-5p inhibitor in SRA01/04 cells. (A) mRNA expression levels of TUG1 in SRA01/04 cells were analyzed using reverse transcription-quantitative PCR following transfection. mRNA expression levels of miR-196a-5p in SRA01/04 cells were analyzed using reverse transcription-quantitative PCR following (B) transfection with miR-196a-5p inhibitor or (C) co-transfection with the miR-196a-5p inhibitor and TUG1-siRNA. ${ }^{* *} \mathrm{P}<0.01$ vs. control-siRNA; ${ }^{\# \#} \mathrm{P}<0.01$ vs. inhibitor control; ${ }^{\&}{ }^{\&} \mathrm{P}<0.01$ vs. TUG1-siRNA + inhibitor control. TUG1, taurine upregulated 1; miR, microRNA; siRNA, small interfering RNA.

the mimic control and TUG1-WT, the luciferase activity of cells co-transfected with miR-196a-5p mimic and TUG1-WT was significantly reduced (Fig. 1B). By contrast, the luciferase activity of cells co-transfected with miR-196a-5p mimic and TUG1-MUT demonstrated no significant changes compared with the luciferase activity of cells co-transfected with mimic control and TUG1-MUT (Fig. 1B).

Expression levels of TUG1 and miR-196a-5p in SRA01/04 cells after $\mathrm{H}_{2} \mathrm{O}_{2}$ treatment. The expression levels of TUG1 and miR-196a-5p in SRA01/04 cells were analyzed using RT-qPCR after cells were exposed to $\mathrm{H}_{2} \mathrm{O}_{2}$ for $24 \mathrm{~h}$. As shown in Fig. 2A and B, compared with those in the control group, the expression levels of TUG1 were significantly upregulated in the $\mathrm{H}_{2} \mathrm{O}_{2}$ group, whilst the expression levels of miR-196a-5p were significantly downregulated.

TUG1 negatively regulates the expression of miR-196a-5p in SRA01/04 cells. SRA01/04 cells were transfected with
TUG1-siRNA or the miR-196a-5p inhibitor for $24 \mathrm{~h}$ before RT-qPCR was performed to determine the transfection efficiency. Compared with those in the control-siRNA or inhibitor control groups, transfection with TUG1-siRNA or the miR-196a-5p inhibitor significantly downregulated the expression levels of TUG1 and miR-196a-5p in SRA01/04 cells, respectively (Fig. 3A and B). In addition, compared with those in the control-siRNA group, transfection with TUG1-siRNA significantly upregulated the expression levels of miR-196a-5p in SRA01/04 cells, which was significantly reversed following co-transfection with the miR-196a-5p inhibitor (Fig. 3C).

miR-196a-5p inhibitor reverses the effects of TUG1-siRNA on $\mathrm{H}_{2} \mathrm{O}_{2}$-induced oxidative damage of SRA01/04 cells. SRA01/04 cells were exposed to $\mathrm{H}_{2} \mathrm{O}_{2}$ following transfection for $24 \mathrm{~h}$ and were subsequently divided into the following six groups: i) Control group; ii) $\mathrm{H}_{2} \mathrm{O}_{2}$ group; iii) $\mathrm{H}_{2} \mathrm{O}_{2}+$ control-siRNA group; iv) $\mathrm{H}_{2} \mathrm{O}_{2}+$ TUG1-siRNA group; v) $\mathrm{H}_{2} \mathrm{O}_{2}+$ TUG1-siRNA + inhibitor control group; and vi) $\mathrm{H}_{2} \mathrm{O}_{2}+$ TUG1-siRNA + 
A

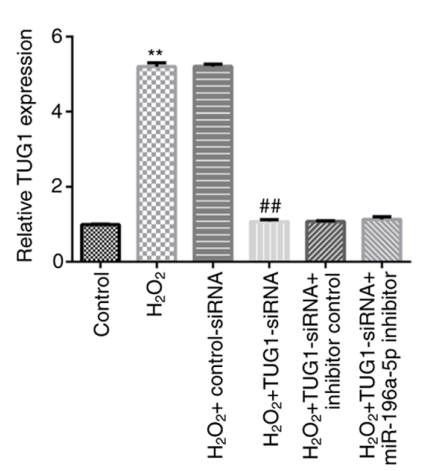

B

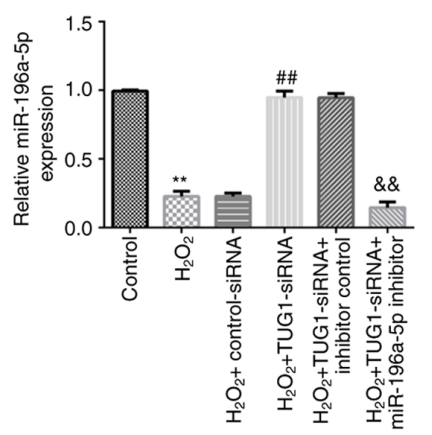

C

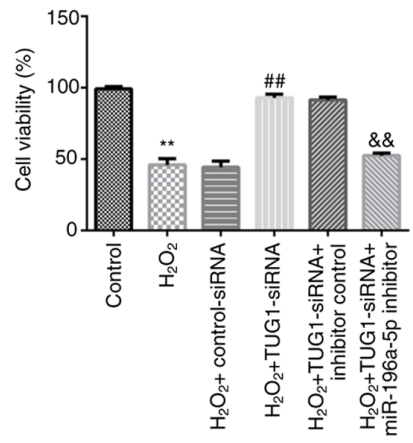

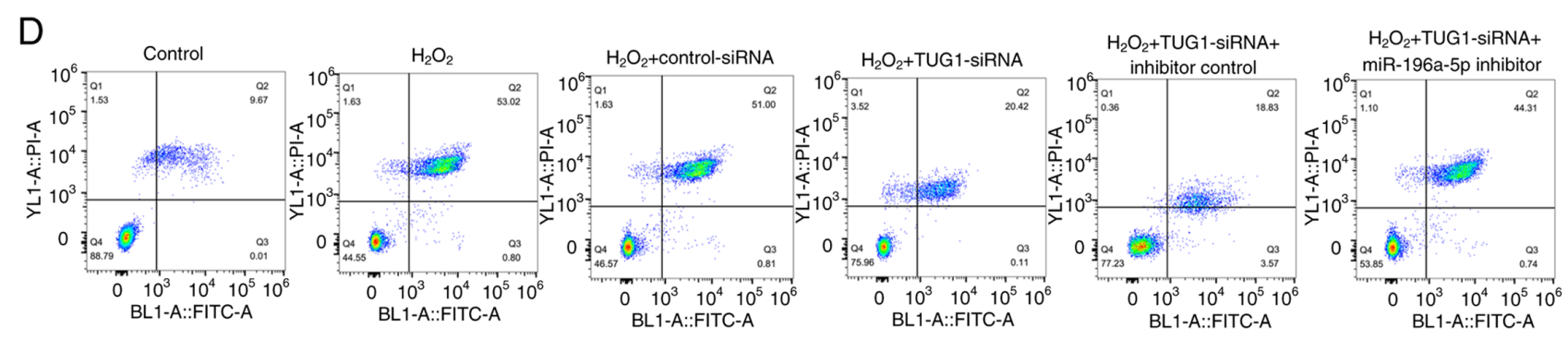

$\mathrm{E}$

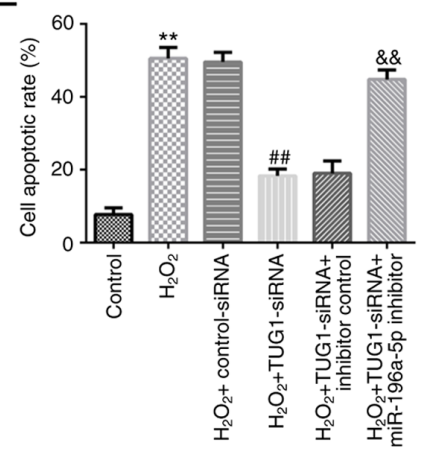

$\mathrm{F}$

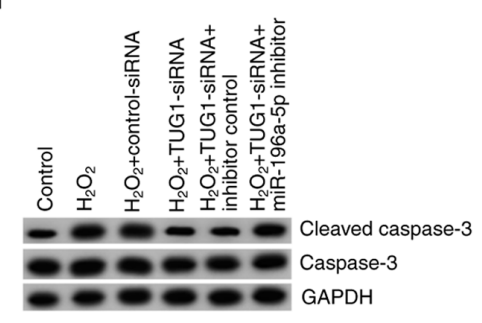

G

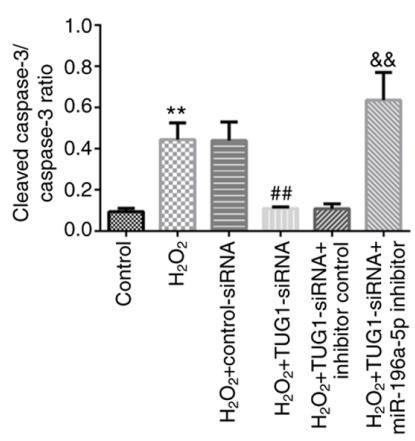

Figure 4. Knockdown of miR-196a-5p abolishes the effects of TUG1-siRNA on $\mathrm{H}_{2} \mathrm{O}_{2}$-induced SRA01/04 cell oxidative damage. Reverse transcription-quantitative PCR was performed to analyze the relative expression levels of (A) TUG1 and (B) miR-196a-5p in SRA01/04 cells. (C) Viability of SRA01/04 cells was measured using MTT assay. (D) Flow cytometric analysis of apoptosis in SRA01/04 cells induced by $\mathrm{H}_{2} \mathrm{O}_{2}$ after co-transfection with TUG1 siRNA and miR-196a-5p, (E) which was quantified. (F) Protein expression levels of cleaved caspase-3 and caspase-3 in SRA01/04 cells were analyzed using western blotting. (G) Ratio of cleaved caspase-3/caspase-3 in SRA01/04 cells was quantified. ${ }^{* *} \mathrm{P}<0.01$ vs. control; ${ }^{\# /} \mathrm{P}<0.01$ vs. $\mathrm{H}_{2} \mathrm{O}_{2}+$ control-siRNA; \&\& $\mathrm{P}<0.01$ vs. $\mathrm{H}_{2} \mathrm{O}_{2}+\mathrm{TUG1}$-siRNA + inhibitor control. miR, microRNA; TUG1, taurine upregulated 1; siRNA, small interfering RNA; $\mathrm{H}_{2} \mathrm{O}_{2}$, hydrogen peroxide.

miR-196a-5p inhibitor group. Compared with those in the control group, TUG1 expression levels were significantly upregulated in the $\mathrm{H}_{2} \mathrm{O}_{2}$ group, whilst the expression levels of miR-196a-5p were significantly downregulated (Fig. 4A and B). Compared with those in the $\mathrm{H}_{2} \mathrm{O}_{2}+$ control-siRNA group, TUG1 expression levels were significantly downregulated in the $\mathrm{H}_{2} \mathrm{O}_{2}$ + TUG1-siRNA group (Fig. 4A). In addition, compared with those in the $\mathrm{H}_{2} \mathrm{O}_{2}+$ control-siRNA group, miR-196a-5p expression levels were found to be significantly upregulated in the $\mathrm{H}_{2} \mathrm{O}_{2}+$ TUG1-siRNA group (Fig. 4B). Notably, this effect was reversed following co-transfection with the miR-196a-5p inhibitor (Fig. 4B).

In addition, the viability, apoptosis, and expression levels of cleaved caspase-3 and caspase-3 were analyzed in SRA01/04 cells. Compared with that in the control group, the viability of cells in the $\mathrm{H}_{2} \mathrm{O}_{2}$ group was significantly reduced (Fig. 4C), whilst the cell apoptotic rate, protein expression levels of cleaved caspase- 3 and the cleaved caspase-3/caspase- 3 ratio were significantly increased in the $\mathrm{H}_{2} \mathrm{O}_{2}$ group (Fig. 4D and E). By contrast, compared with that in the $\mathrm{H}_{2} \mathrm{O}_{2}+$ control-siRNA group, the viability of cells in the $\mathrm{H}_{2} \mathrm{O}_{2}+$ TUG1-siRNA group was significantly increased (Fig. 4C), whilst the cell apoptotic rate, protein expression levels of cleaved caspase- 3 and the cleaved caspase-3/caspase-3 ratio were significantly reduced (Fig. 4D and E). All of these effects aforementioned were found to be significantly reversed following co-transfection with the miR-196a-5p inhibitor.

miR-196a-5p attenuates $\mathrm{H}_{2} \mathrm{O}_{2}$-induced oxidative damage in SRA01/04 cells. SRA01/04 cells were exposed to $\mathrm{H}_{2} \mathrm{O}_{2}$ following $24 \mathrm{~h}$ of transfection and subsequently divided into the following four groups: i) Control group; ii) $\mathrm{H}_{2} \mathrm{O}_{2}$ group; iii) $\mathrm{H}_{2} \mathrm{O}_{2}$ + mimic control group; and iv) $\mathrm{H}_{2} \mathrm{O}_{2}+$ miR-196a-5p mimic group. Transfection with the miR-196a-5p mimic significantly upregulated the expression levels of miR-196a-5p in SRA01/04 cells (Fig. 5A), suggesting the successful transfection of the miR-196a-5p mimic. Subsequently, the underlying molecular mechanism of miR-196a-5p in SRA01/04 cells was investigated. Compared with those in the control group, miR-196a-5p 
A

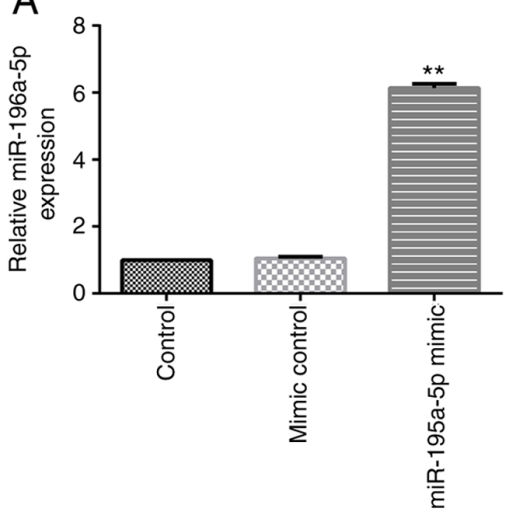

B

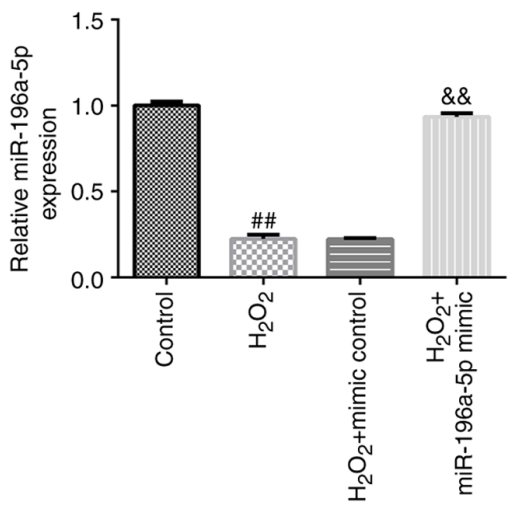

C

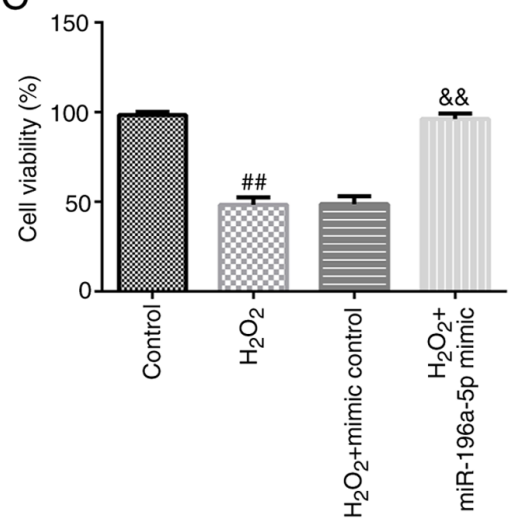

D

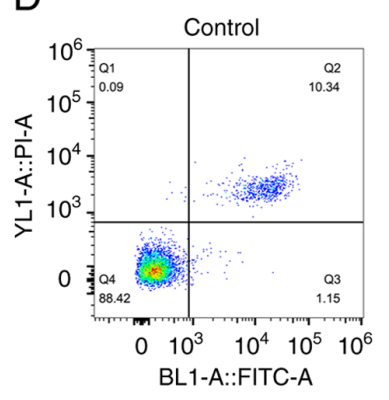

E

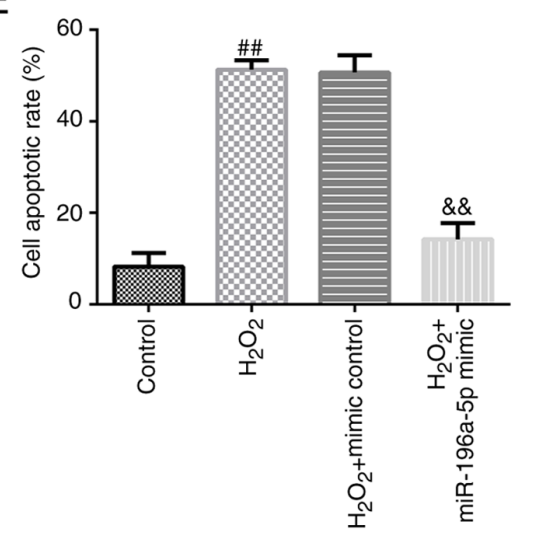

$\mathrm{H}_{2} \mathrm{O}_{2}$

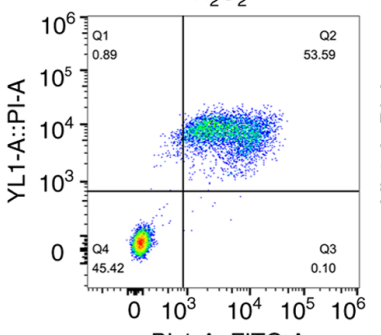

BL1-A::FITC-A

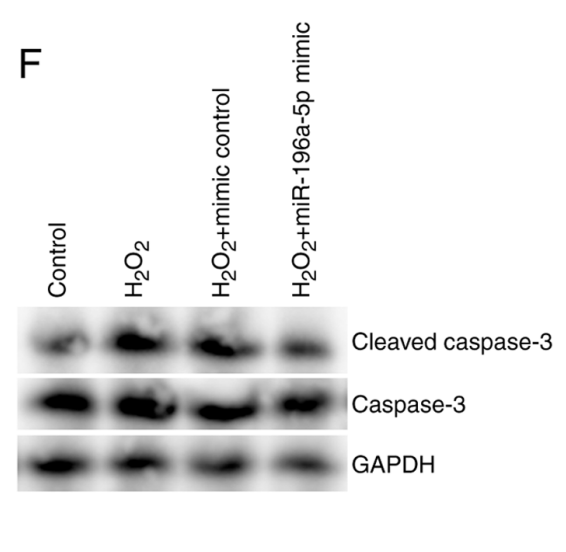

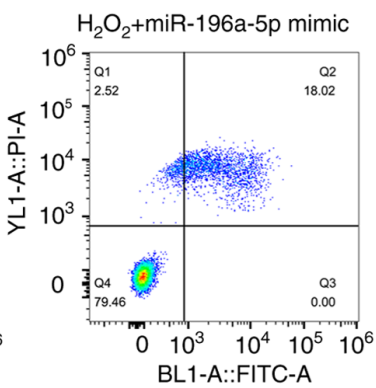

G

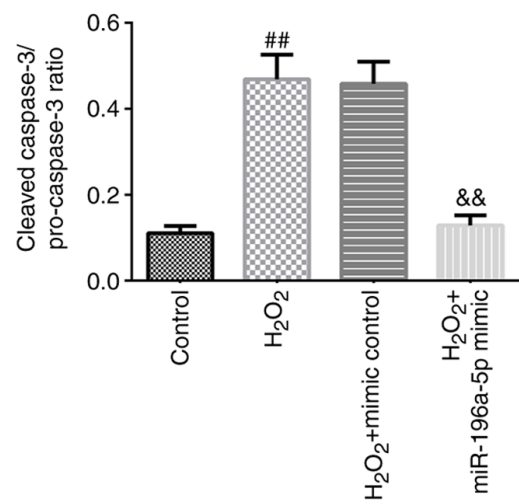

Figure 5. miR-196a-5p overexpression attenuates $\mathrm{H}_{2} \mathrm{O}_{2}$-induced oxidative damage in SRA01/04 cells. Reverse transcription-quantitative PCR was performed to analyze the relative expression levels of miR-196a-5p (A) in cells transfected with the miR-196a-5p mimic and (B) in cells transfected with the miR-196a-5p mimic and treated with $\mathrm{H}_{2} \mathrm{O}_{2}$. (C) Viability of SRA01/04 cells was detected using MTT assay. (D) Flow cytometry analysis of cell apoptosis in SRA01/04 cells following treatment with $\mathrm{H}_{2} \mathrm{O}_{2}$ and transfection with the miR-196a-5p mimic, (E) which was quantified. (F) Protein expression levels of cleaved caspase-3 and caspase-3 in SRA01/04 cells were analyzed by western blotting. (G) Ratio of cleaved caspase-3/caspase-3 in SRA01/04 cells was quantified. ${ }^{* *} \mathrm{P}<0.01$ vs. mimic control; ${ }^{\#} \mathrm{P}<0.01$ vs. control; ${ }^{\& \&} \mathrm{P}<0.01$ vs. $\mathrm{H}_{2} \mathrm{O}_{2}+$ mimic control. miR, microRNA; $\mathrm{H}_{2} \mathrm{O}_{2}$, hydrogen peroxide.

expression levels and cell viability were significantly reduced in the $\mathrm{H}_{2} \mathrm{O}_{2}$ group (Fig. 5B and C), whilst the apoptosis levels, protein expression levels of cleaved caspase- 3 and the cleaved caspase-3/caspase-3 ratio were all significantly increased (Fig. 5D-G). Conversely, compared with those in the $\mathrm{H}_{2} \mathrm{O}_{2}+$ mimic control group, miR-196a-5p expression levels and cell viability were significantly increased in the $\mathrm{H}_{2} \mathrm{O}_{2}+$ miR-196a-5p mimic group (Fig. 5B and C), whilst the levels of apoptosis, protein expression levels of cleaved caspase- 3 and the cleaved caspase-3/caspase-3 ratio were significantly reduced (Fig. 5D-G).

\section{Discussion}

Age-related cataracts is a type of degenerative disease as a complication of aging, where its pathogenesis is closely associated with cellular senescence and decreased metabolic function in the lens (35). The incidence of age-related cataracts increases with age; 43-54-year-old patients have an incidence of $8.3 \%$, compared with an incidence as high as $70.5 \%$ in patients over $75(14,15)$. Oxidative stress occurs when the oxidative and antioxidant mechanisms in the body become unbalanced, such that an enhanced oxidative state is favored $(36,37)$. This then promotes inflammatory infiltration by neutrophils, increased secretion of proteases and the production of large quantities of reactive oxidative intermediate products $(36,37)$. Oxidative stress is an adverse effect that is caused by the production and accumulation of free radicals in the body, which is considered to be an important contributing factor to aging and disease (38). It was previously reported that oxidative stress serves an important role in the 
pathogenesis of various types of cataracts $(39,40)$. Age-related cataracts are mainly caused by oxygen free radical-induced damage to LECs, which prompts conformational changes in important proteins, such as E3 ubiquitin-protein ligase Mdm2 and Rho-associated protein kinase 1 in LECs $(41,42)$. To study the role of lncRNA TUG1 in age-related cataracts in vitro, the present study established an in vitro oxidative stress model by exposing the LEC line, SRA01/04, to $200 \mu \mathrm{M} \mathrm{H}_{2} \mathrm{O}_{2}$ for $24 \mathrm{~h}$.

LncRNA TUG1 is expressed in the retina and brain and was discovered to serve an important role in numerous cancer types, including colorectal, esophageal and bladder cancer (43-45). However, to the best of our knowledge, the underlying mechanism of action of TUG1 in age-related cataracts remains to be determined. To investigate the underlying mechanisms of TUG1 in age-related cataracts, the present study predicted and verified the binding site between TUG1 and miR-196a-5p. Through bioinformatics software analysis, it was found that there may be a binding site between miR-196a-5p and TUG1. Therefore, TUG1 may regulate the proliferation and apoptosis of lens epithelial cells by regulating the expression of miR-196a-5p, thereby participating in the occurrence of age-related cataracts. In addition, the expression levels of TUG1 were found to be upregulated, whilst miR-196a-5p expression levels were downregulated, in SRA01/04 cells induced by $\mathrm{H}_{2} \mathrm{O}_{2}$. Subsequent transfection experiments revealed that TUG1 negatively regulated miR-196a-5p expression in SRA01/04 cells. However, whether the overexpression of TUG1 has a significant inhibiting effect on miR-196a-5p was not studied in the present study and is a limitation.

To determine the effects of TUG1 on $\mathrm{H}_{2} \mathrm{O}_{2}$-induced oxidative damage in SRA01/04 cells and miR-196a-5p expression, cell function experiments were performed in SRA01/04 cells following TUG1 knockdown. Results from the present study revealed that transfection with TUG1-siRNA reduced the $\mathrm{H}_{2} \mathrm{O}_{2}$-induced oxidative damage, which was evidenced by the increased cellviability, reduced cell apoptosis,cleaved-caspase 3 protein expression and reduced cleaved-caspase3/caspase 3 ratios in SRA01/04 cells. By contrast, co-transfection with the miR-196a-5p inhibitor reversed these effects aforementioned. In addition, the overexpression of miR-196a-5p attenuated $\mathrm{H}_{2} \mathrm{O}_{2}$-induced oxidative damage in SRA01/04 cells. It was worth mentioning that the apoptosis rate of $\mathrm{H}_{2} \mathrm{O}_{2}+$ TUG1-siRNA + miR-196a-5p inhibitor group was similar to that in the $\mathrm{H}_{2} \mathrm{O}_{2}$ and $\mathrm{H}_{2} \mathrm{O}_{2}+$ control-siRNA group. However, the ratio of cleaved-caspase 3 /caspase 3 in the $\mathrm{H}_{2} \mathrm{O}_{2}$ + TUG1-siRNA + miR-196a-5p inhibitor group, was higher compared with that in the $\mathrm{H}_{2} \mathrm{O}_{2}$ and $\mathrm{H}_{2} \mathrm{O}_{2}+$ control-siRNA group. The reason for this difference between the apoptosis rate and the cleaved-caspase $3 /$ caspase 3 ratio remain unclear, which require further study.

In conclusion, the findings of the present study revealed that knockdown of lncRNA TUG1 expression protected LECs from oxidative stress-induced apoptosis by increasing miR-196a-5p expression. These results suggest that targeting TUG1 and miR-196a-5p may provide a new therapeutic strategy for patients with age-related cataracts.

\section{Acknowledgements}

Not applicable.

\section{Funding}

No funding was received.

\section{Availability of data and materials}

The datasets used and/or generated during the current study are available from the corresponding author on reasonable request.

\section{Authors' contributions}

QS contributed to study design, data collection, statistical analysis, data interpretation and manuscript preparation. TZ contributed to data collection, statistical analysis and manuscript preparation. QS and TZ confirm the authenticity of all the raw data. All authors read and approved the final manuscript.

\section{Ethics approval and consent to participate}

Not applicable.

\section{Patient consent for publication}

Not applicable.

\section{Competing interests}

The authors declare that they have no competing interests.

\section{References}

1. Thompson J and Lakhani N: Cataracts. Prim Care 42: 409-423, 2015.

2. Shiels A and Hejtmancik JF: Biology of inherited cataracts and opportunities for treatment. Annu Rev Vis Sci 5: 123-149, 2019.

3. Vrensen GF: Early cortical lens opacities: A short overview. Acta Ophthalmol 87: 602-610, 2009.

4. Ten Berge JC, Fazil Z, van den Born I, Wolfs RCW, Schreurs MWJ, Dik WA and Rothova A: Intraocular cytokine profile and autoimmune reactions in retinitis pigmentosa, age-related macular degeneration, glaucoma and cataract. Acta Ophthalmol 97: 185-192, 2019.

5. Lee CM and Afshari NA: The global state of cataract blindness Curr Opin Ophthalmol 28: 98-103, 2017.

6. Olson RJ, Braga-Mele R, Chen SH, Miller KM, Pineda R II, Tweeten JP and Musch DC: Cataract in the adult eye preferred practice pattern ${ }^{\circledR}$. Ophthalmology 124: P1-P119, 2017.

7. Yuan XB, Zhang DY, Chen SJ, Wu PC and Zhang WF: Prevalence of cataract among the population aged 50 years and over at different altitudes in Gansu Province. Zhonghua Yan Ke Za Zhi 55: 589-594, 2019 (In Chinese).

8. Asbell PA, Dualan I, Mindel J, Brocks D, Ahmad M and Epstein S: Age-related cataract. Lancet 365: 599-609, 2005.

9. Shiels A and Hejtmancik JF: Mutations and mechanisms in congenital and age-related cataracts. Exp Eye Res 156: 95-102, 2017.

10. Liu YC, Wilkins M, Kim T, Malyugin B and Mehta JS: Cataracts. Lancet 390: 600-612, 2017.

11. Keel S and He M: Risk factors for age-related cataract. Clin Exp Ophthalmol 46: 327-328, 2018.

12. Hashemi H, Pakzad R, Yekta A, Aghamirsalim M, Pakbin M, Ramin S and Khabazkhoob M: Global and regional prevalence of age-related cataract: A comprehensive systematic review and meta-analysis. Eye (Lond) 34: 1357-1370, 2020.

13. National Institute for Health and Care Excellence (UK): Cataracts in adults: Management. National Institute for Health and Care Excellence, London, 2017.

14. Truscott RJW and Friedrich MG: Molecular processes implicated in human age-related nuclear cataract. Invest Ophthalmol Vis Sci 60: 5007-5021, 2019. 
15. Klein BE, Klein R and Lee KE: Incidence of age-related cataract: The beaver dam eye study. Arch Ophthalmol 116: 219-225, 1998.

16. Lu B, Christensen IT, Yu T, Wang C, Yan Q and Wang X: SUMOylation evoked by oxidative stress reduced lens epithelial cell antioxidant functions by increasing the stability and transcription of TP53INP1 in age-related cataracts. Oxid Med Cell Longev 2019: 7898069, 2019.

17. Yang H, Cui Y, Tang Y, Tang X, Yu X, Zhou J, Yin Q and Shentu X: Cytoprotective role of humanin in lens epithelial cell oxidative stress-induced injury. Mol Med Rep 22: 1467-1479, 2020.

18. Panni S, Lovering RC, Porras P and Orchard S: Non-coding RNA regulatory networks. Biochim Biophys Acta Gene Regul Mech 1863: 194417, 2020.

19. Puvvula PK: LncRNAs regulatory networks in cellular senescence. Int J Mol Sci 20: 2615, 2019.

20. He Z, Yang D, Fan X, Zhang M, Li Y, Gu X and Yang M: The roles and mechanisms of lncRNAs in liver fibrosis. Int $\mathrm{J}$ Mol Sci 21: 1482, 2020.

21. Wang J and Cen S: Roles of lncRNAs in influenza virus infection. Emerg Microbes Infect 9: 1407-1414, 2020.

22. Correia de Sousa M, Gjorgjieva M, Dolicka D, Sobolewski C and Foti M: Deciphering miRNAs' action through miRNA editing. Int J Mol Sci 20: 6249, 2019.

23. Ghafouri-Fard S, Shoorei $\mathrm{H}$ and Taheri M: miRNA profile in ovarian cancer. Exp Mol Pathol 113: 104381, 2020.

24. Permenter MG, McDyre BC, Ippolito DL and Stallings JD: Alterations in tissue microRNA after heat stress in the conscious rat: Potential biomarkers of organ-specific injury. BMC Genomics 20: 141, 2019.

25. Chen X, Xiao W, Chen W, Liu X, Wu M, Bo Q, Luo Y, Ye S, Cao Y and Liu Y: MicroRNA-26a and -26b inhibit lens fibrosis and cataract by negatively regulating Jagged-1/Notch signaling pathway. Cell Death Differ 24: 1431-1442, 2017.

26. Zhang F, Meng W and Tong B: Down-regulation of MicroRNA-133b suppresses apoptosis of lens epithelial cell by up-regulating BCL2L2 in age-related cataracts. Med Sci Monit 22: 4139-4145, 2016.

27. Li G, Song H, Chen L, Yang W, Nan K and Lu P: TUG1 promotes lens epithelial cell apoptosis by regulating miR-421/caspase-3 axis in age-related cataract. Exp Cell Res 356: 20-27, 2017.

28. Xin H, Wang C and Liu Z: miR-196a-5p promotes metastasis of colorectal cancer via targeting IкB $\alpha$. BMC Cancer 19: 30, 2019.

29. Mi C, Ye B, Gao Z, Du J, Li R and Huang D: BHLHE40 plays a pathological role in pre-eclampsia through upregulating SNX16 by transcriptional inhibition of miR-196a-5p. Mol Hum Reprod 26: 532-548, 2020.

30. Zhang L, Xie H and Li S: LncRNA LOXL1-AS1 controls osteogenic and adipocytic differentiation of bone marrow mesenchymal stem cells in postmenopausal osteoporosis through regulating the miR-196a-5p/Hmga2 axis. J Bone Miner Metab 38: 794-805, 2020.

31. Wang L, Wei Y, Yan Y, Wang H, Yang J, Zheng Z, Zha J, Bo P Tang Y, Guo X, et al: CircDOCK1 suppresses cell apoptosis via inhibition of miR-196a-5p by targeting BIRC 3 in OSCC. Oncol Rep 39: 951-966, 2018.
32. Yang JP, Yang JK, Li C, Cui ZQ, Liu HJ, Sun XF, Geng SM, Lu SK, Song J, Guo CY and Jiao BH: Downregulation of ZMYND11 induced by miR-196a-5p promotes the progression and growth of GBM. Biochem Biophys Res Commun 494: 674-680, 2017.

33. Tu Y, Li L, Qin B, Wu J, Cheng T, Kang L and Guan H: Long noncoding RNA glutathione peroxidase 3 -antisense inhibits lens epithelial cell apoptosis by upregulating glutathione peroxidase 3 expression in age-related cataract. Mol Vis 25: 734-744, 2019.

34. Livak KJ and Schmittgen TD: Analysis of relative gene expression data using real-time quantitative PCR and the 2(-Delta Delta C(T)) method. Methods 25: 402-408, 2001.

35. Fukuoka $\mathrm{H}$ and Afshari NA: The impact of age-related cataract on measures of frailty in an aging global population. Curr Opin Ophthalmol 28: 93-97, 2017.

36. Chainy GBN and Sahoo DK: Hormones and oxidative stress: An overview. Free Radic Res 54: 1-26, 2020.

37. Chirumbolo S: Oxidative stress, nutrition and cancer: Friends or foes? World J Mens Health 39: 19-30, 2021.

38. Shao A, Lin D, Wang L, Tu S, Lenahan C and Zhang J: Oxidative stress at the crossroads of aging, stroke and depression. Aging Dis 11: 1537-1566, 2020.

39. Wu C, Liu Z, Ma L, Pei C, Qin L, Gao N, Li J and Yin Y: MiRNAs regulate oxidative stress related genes via binding to the 3' UTR and TATA-box regions: A new hypothesis for cataract pathogenesis. BMC Ophthalmol 17: 142, 2017.

40. Liu XF, Hao JL, Xie T, Malik TH, Lu CB, Liu C, Shu C, Lu CW and Zhou DD: Nrf2 as a target for prevention of age-related and diabetic cataracts by against oxidative stress. Aging Cell 16: 934-942, 2017.

41. Wang Z, Su D, Sun Z, Liu S, Sun L, Li Q, Guan L, Liu Y, Ma X and $\mathrm{Hu}$ S: MDM2 phosphorylation mediates $\mathrm{H}_{2} \mathrm{O}_{2}$-induced lens epithelial cells apoptosis and age-related cataract. Biochem Biophys Res Commun 528: 112-119, 2020.

42. Hu S, Su D, Sun L, Wang Z, Guan L, Liu S, Zhao B, Liu Y, Shi C, Yu J and Ma X: High-expression of ROCK1 modulates the apoptosis of lens epithelial cells in age-related cataracts by targeting p53 gene. Mol Med 26: 124, 2020

43. Yan Z, Bi M, Zhang Q, Song $Y$ and Hong S: LncRNA TUG1 promotes the progression of colorectal cancer via the miR-138-5p/ZEB2 axis. Biosci Rep 40: BSR20201025, 2020.

44. Zong M, Feng W, Wan L, Yu X and Yu W: LncRNA TUG1 promotes esophageal cancer development through regulating PLK1 expression by sponging miR-1294. Biotechnol Lett 42: 2537-2549, 2020.

45. Yu G, Zhou H, Yao W, Meng L and Lang B: lncRNA TUG1 promotes cisplatin resistance by regulating CCND2 via epigenetically silencing miR-194-5p in bladder cancer. Mol Ther Nucleic Acids 16: 257-271, 2019.

This work is licensed under a Creative Commons Attribution-NonCommercial-NoDerivatives 4.0 International (CC BY-NC-ND 4.0) License. 